\title{
Roof Pond with Intermittent Pumping as Passive Cooling alternative for Reinforced Cement Concrete Roof Top Slab
}

\author{
Sanjay V. Lipare ${ }^{1}$, Nagaraj S. Patil ${ }^{2}$, Suresh G. Patil ${ }^{3}$, Avinash M. Potdar ${ }^{4}$ \\ KIT's College of Engineering, Kolhapur, Maharashtra, India ${ }^{1}$, \\ Visveswarya Technological University, Belagavi, Karanataka, India ${ }^{1,2}$, \\ P. D. A. Engineering College, Kalburgi, Karanataka, India ${ }^{3}$. \\ sanjaylipare13@gmail.com
}

\begin{abstract}
RCC roof slab retains more thermal energy when it is exposed to sunlight. This increases the room temperature. The increased temperature creates unacceptable thermal comfort to the occupants. In this paper, authors are investigating the effect of suggested passive cooling method to reduce the storage of thermal energy into the RCC roof slab. The roof exposed to sunlight is the most critical part of residential buildings. Indoor residential do not provide thermal comfort to occupants during peak summer, which creates an undesirable effect on occupant's ability to function properly. Mechanical cooling devices like air conditioners are not environment-friendly and energy sustainable. The response time of the passive cooling system to irradiation remains slow. This is a desirable behaviour to control thermal variations which in turn moderates thermal loads concurrently. The author's proposed the open pond with intermittent pumping which achieves the thermal comfort. The authors' seminal efforts are to design the passive cooling roof slab with minimal use of energy and further directions for the sustainability of energy systems, impact on day to day activity.
\end{abstract}

Keywords:Passive cooling; Roof pond; Thermal comfort; Energy conservation

\section{Introduction}

Most of the modern buildings are made of concrete structures. The buildings prepared of concrete can hold unwanted hotness for an extended duration of time. In the daytime, a large portion of concrete roofs gets heated up by sun rays. This will intern transfers heats to the room immediately below. The contribution of the roof to the total heat gain by the building is $50 \%$ [1]. This is major compared to the external walls of the buildings. This is the reason why authors' have limited their scope to the roof for passive cooling of the building. The increased temperature creates unacceptable thermal comfort to the occupants. Fans and air conditioners are used to reduce 
room temperature and achieve thermal comforts. This dependency increases the cost of thermal comfort to install, operate and maintain the mechanical ventilation.

Any method applied to the building which decreases its cooling load, such as solar rays control management, reducing indoor heat gain, etc., termed as passive cooling techniques [2]. The evaporation occurs with the phase change of water fluid to vapor. It results in the cooling of water. The maximum cooling is function of wet bulb temperature and dry bulb temperature [3]. Passive cooling systems or design features adopted to cool buildings and workplaces without or with minimal energy usage to improve their energy efficiency [4]. When energy usage occurs, this one is less as compared to the usage of the active methods. Passive cooling will be required in tropical countries. This will reduce the cooling load and energy consumption. The authors' suggest here an alternative method of passive cooling of roof pond using intermittent pumping. The cool water from an underground water tank is intermittently pumped to the roof pond. This water absorbs the heat from sunlight. Water in the roof pond is refreshed when its temperature approaches near to ambient temperature. The heated water is recycled to an underground water tank through a sand filter. The temperature of slab top, bottom, environment, with and without roof pond is recorded. The difference in rooftop temperature with and without intermittent pumping roof pond is $14{ }^{\circ} \mathrm{C}$. The cost analysis comparison is done for a roof pond with intermittent pumping and the conventional standard air condition equipment.

\section{Review on passive cooling system design}

Water splash rooftops, wetted roof, humid porous media, roof pond, and roof pond with cotton fabric floating at the water surface, cool pool, and gunny bags. Further clarification is the rooftop pond with mobile protection, which can accomplish comfort conditions in a dry region [5]. However, air conditioning power consumption records over half of the complete energy used by buildings. The power consumption of air conditioning arrangements can thus be considerably decreased by decreasing the heat spreads to the buildings [4]. The consequence of night ventilation is very powerful for structures with more thermal mass however not for those structures with a less thermal mass. The usage of the structure's thermal mass serves to smooth out peaks in power requirement. With the development in population and economy give rise to growing demands for housing in developed areas. The developed roof area and road surface cover $60 \%$ of town spaces. The superficial hotness in urban communities would extraordinarily improve in the following 10 years or less because of the increase in the population [6]. It is possible to achieve air temperature at $75 \%$ of the difference between dry-bulb temperature and wet bulb temperature. Thus evaporative cooling is based on wet bulb temperature [3]. The temperature of room increases beyond the thermal comfort of a human if doors and windows are closed in a modern low-income house. The required ventilation must be provided to get thermal comfort [6]. 


\section{$3 \quad$ Material and Methodology}

A roof pond open to the sky is used here with modification of water replacement at stipulated time. This time is decided by observation of temperature of water in the pond exposed to sunlight. The water will get heated with sunlight falling on it. When water gets heated by 4 to $6{ }^{\circ} \mathrm{C}$, this is the time to replace it with cold water from an underground tank. Water in the underground water tank usually remains cool for the whole day. The temperature varies from $26^{\circ} \mathrm{C}$ to $28^{\circ} \mathrm{C}$. This water can be used as a cooling medium to cool the RCC roof slab. This cool water is pumped at multiple times in a day. The water is pumped at morning 10:30 am and 12:30 pm. It is pumped during the peak temperature hours of the day typically at 2:00 pm and 3:00 $\mathrm{pm}$. After this time the temperature of pond water drops below ambient temperature. Hence the same water is kept overnight to till the next day morning. Used water goes again to the underground tank through a sand filter. Thus the water is a precious commodity it is saved and recycled. The underground tank is of $1.5 \mathrm{~m}$ depth. The water is heated just by 3 to $4{ }^{\circ} \mathrm{C}$ does not increase the temperature of water in the underground tank. Used water is released at the top level of the tank while water is drawn from the bottom of the tank. Also, night ventilation allowed rejecting heat from building thermal mass. While day time minimum ventilation allowed to avoid the entry of hot outside air. The methodology was adopted to the full-scale residential building of ground plus one storey as shown in fig. 1. It has the cross-section of roof slab as shown in fig. 2.

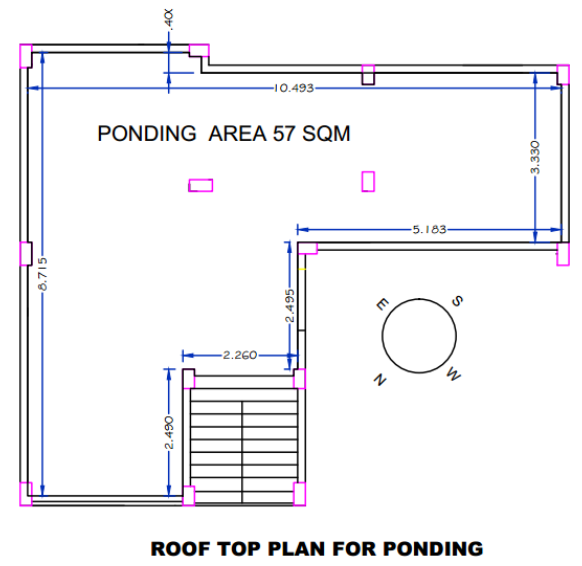

Fig. 1.Plan of RCC Roof used as an open pond

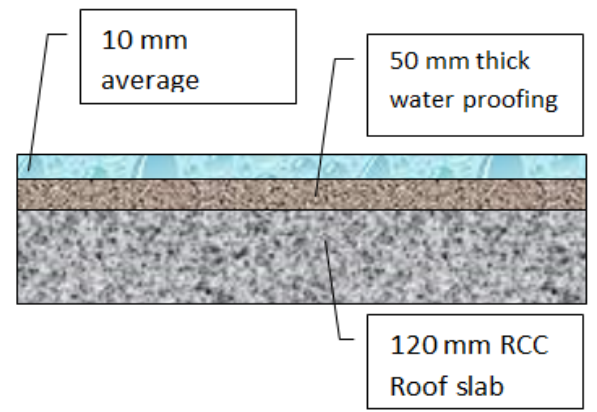


Fig. 2.Cross-section of RCC Roof used as an open pond

\subsection{The geographical location of the site}

In the case of tropical cities like Kolhapur which is at $593 \mathrm{~m}$ above MSL, longitude $74.25^{\circ} \mathrm{E}$ and latitude is $16.66^{\circ} \mathrm{N}$. The climate of Kolhapur is a mixture of inland and coastal. Kolhapur has three-season viz. monsoon, winter and summer. The temperature of Kolhapur ranges from $10{ }^{\circ} \mathrm{C}$ to $35^{\circ} \mathrm{C}$. Summer is normally experienced from March to May. Summer remains much more humid, compared to nearby areas. Temperatures normally not go beyond $39^{\circ} \mathrm{C}$ during summer and typically remain from 32 to $36{ }^{\circ} \mathrm{C}$. It reaches to the lower value of $24{ }^{\circ} \mathrm{C}$ to $26^{\circ} \mathrm{C}$ during summer nighttime.Winter is normally observed from November to February. The temperature during winter ranges from $10{ }^{\circ} \mathrm{C}$ to $16^{\circ} \mathrm{C}$ whereas the maximum is in the range of $26^{\circ} \mathrm{C}$ to $32{ }^{\circ} \mathrm{C}$ due to its higher altitude and being closer to the Western Ghats. Thus climate in this season remains much more pleasant due to low humidity. The rainy season is normally observed from June to September.

\subsection{Thermal Comfort}

Temperature greater than $45^{\circ} \mathrm{C}$ or under $18^{\circ} \mathrm{C}$ creates an uncomfortable situation for the human body. Hotness at 33 to $34^{\circ} \mathrm{C}$ is comfortable when the human body is at an inactive position and reduces with more movement. Internal temperatures of the human body escalate with movement. The temperature administrative focus in the mind is about $36.8^{\circ} \mathrm{C}$ at static in solace and increments to about $37.4^{\circ} \mathrm{C}$ while strolling and $37.9^{\circ} \mathrm{C}$ while running. For the present study, the mean temperature is $28^{\circ} \mathrm{C}$. For this temperature, comfort zones at $90 \%$ acceptability are from $24^{\circ} \mathrm{C}$ to $28.5^{\circ} \mathrm{C}$.

\subsection{Observations}

Thermometers were placed at various locations to inspect their effect in the experiment of passive cooling arrangement. The temperature data were recorded and is same is presented in following table 1 .

Table 1. Observation of Temperature of open pond

\begin{tabular}{|c|c|c|c|c|c|c|}
\hline \multicolumn{2}{|c|}{} & $\begin{array}{r}\text { Outdoor } \\
\text { Air Temp. }{ }^{\circ} \mathrm{C}\end{array}$ & $\begin{array}{r}\text { Room } \\
\text { Temp. }{ }^{\circ} \mathrm{C}\end{array}$ & $\begin{array}{r}\text { Roof Top } \\
\text { Temp. }{ }^{\circ} \mathrm{C}\end{array}$ & $\begin{array}{r}\text { Roof Bot- } \\
\text { tom Temp. }{ }^{\circ} \mathrm{C}\end{array}$ & $\begin{array}{r}\text { Roof Top Temp. } \\
\text { Without pond }{ }^{\circ} \mathrm{C}\end{array}$ \\
\hline $\begin{array}{c}\text { D } \\
\text { ate }\end{array}$ & $\begin{array}{c}\text { Day } \\
\text { hours }\end{array}$ & 1 & 2 & 3 & 4 & 5 \\
\hline
\end{tabular}




\begin{tabular}{|c|c|c|c|c|c|c|}
\hline \multirow{11}{*}{  } & 8:00 & 25.0 & 26.5 & 24.0 & 26.0 & 24.0 \\
\hline & 9:00 & 27.5 & 26.5 & 26.0 & 26.0 & 27.0 \\
\hline & $10: 00$ & 30.5 & 26.5 & 27.5 & 26.0 & 35.0 \\
\hline & $11: 00$ & 32.5 & 27.5 & 29.5 & 27.0 & 40.0 \\
\hline & $12: 00$ & 34.0 & 28.0 & 31.5 & 29.0 & 43.5 \\
\hline & 13:00 & 35.2 & 28.5 & 33.0 & 30.5 & 46.0 \\
\hline & $14: 00$ & 36.0 & 28.8 & 33.5 & 31.0 & 48.0 \\
\hline & $15: 00$ & 36.0 & 29.0 & 33.0 & 31.0 & 47.6 \\
\hline & $16: 00$ & 35.5 & 28.8 & 29.5 & 30.5 & 45.2 \\
\hline & $17: 00$ & 33.5 & 28.5 & 27.5 & 29.0 & 41.0 \\
\hline & 18:00 & 31.5 & 28.2 & 26.5 & 28.0 & 35.0 \\
\hline
\end{tabular}

The temperature data is also presented in pictorial form in the following chart in fig.3.

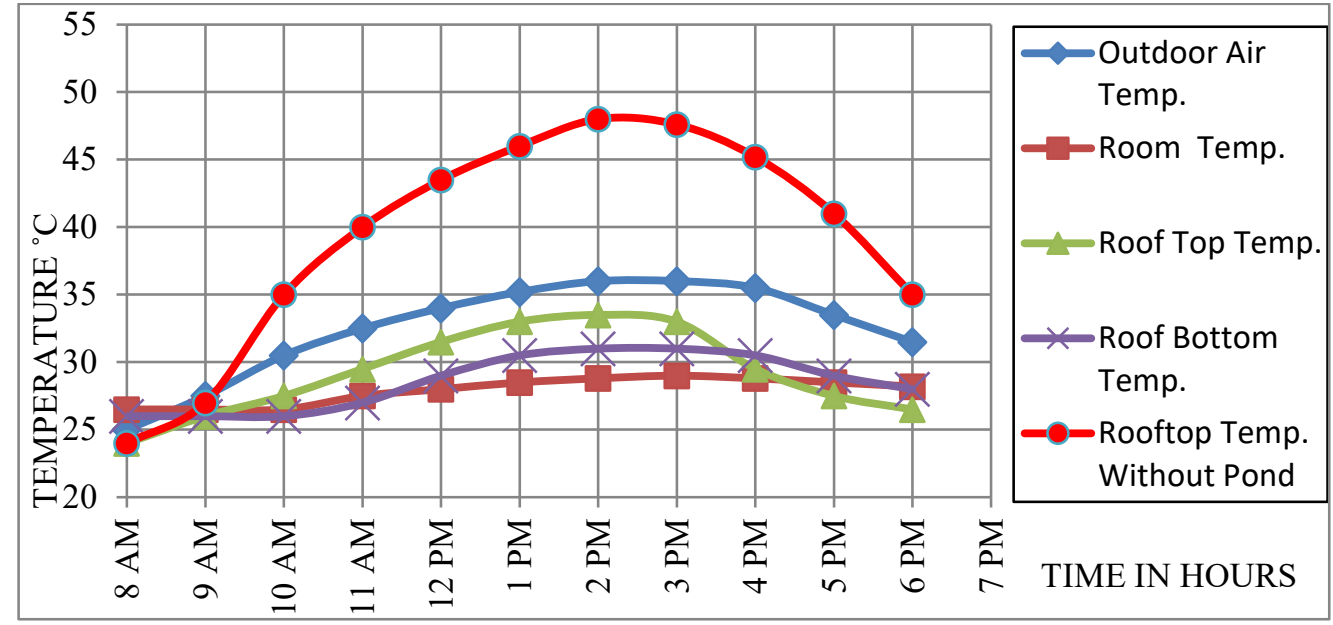

Fig. 3. Pictorial presentation of open pond behaviour

\subsection{Cost analysis and comparison}

\section{Pond with intermittent pumping.}

Area of Roof is $57 \mathrm{Sq}$. M. Average water depth is $10 \mathrm{~mm}$. Water quantity required for one application is 570 liters. Evaporation losses $6 \mathrm{~mm}$ per Sq. M. Water lost in evaporation 342 liters. The $\mathrm{G}+1$ storey is under consideration. The pond is created at the roof of the first floor. Pumping head is $9 \mathrm{~m}$ from the underground tank to overhead tank at $\mathrm{G}+2$. A 0.367 (half $\mathrm{Hp}$ ) pump runs for 30 minutes for one application. Power consumption for four application of water is $0.735 \mathrm{~kW}$-hr per day. Cost of power is ₹5.88/- per day considering the cost of electric power as ₹8/- per unit of one 
$\mathrm{kW}$-hr. Cost of 342 liters water lost in evaporation is ₹5.13/- considering the cost of water as ₹15/- per unit of one kilo-liter. Cost of daily consumption is ₹ $5.88+₹ 5.13=$ ₹11.01 per day. Monthly cost becomes ₹330/-

\section{Standard Air Condition Equipment.}

Master bed of $3 \mathrm{~m} \times 6 \mathrm{~m}, 18 \mathrm{Sq}$. M. which will require $1.5 \mathrm{MT}$ air conditioner. Power consumption is $840 / 1600 \mathrm{kWh}$. Operating it for 4 hours daily, power units will be $2.1 \mathrm{kWh}$. Similarly for Children bed of $3.3 \mathrm{~m}$ x $3.5 \mathrm{~m}, 11.55 \mathrm{Sq}$. M. which will require 1.0 MT air conditioner. Power consumption is $565 / 1600 \mathrm{kWh}$. Operating it for 4 hours daily, power units will be $1.4 \mathrm{kWh}$. Total power consumption is $3.5 \mathrm{kWh}$. The cost of power consumption is ₹28.00/- per day. Monthly cost becomes ₹840/-. The monthly expenses become $39 \%$ compared to air conditioner when passive cooling with intermittent pumping is used. However, it will not replace the AC equipment as it will have its advantages and abilities over the passive cooling techniques.

\section{$4 \quad$ Result and Discussion}

The room temperature remains always around $28^{\circ} \mathrm{C}$ which is comfortable temperature as per ASHRAE. The temperature of the rooftop of the RCC roof increases up to $48^{\circ} \mathrm{C}$ for roof without pond. This heat will transfer at the bottom of the roof and room immediate below it. When the pond is provided with intermittent pumping room temperature remains at $26^{\circ} \mathrm{C}$ to $29^{\circ} \mathrm{C}$. For this condition, as observed readings of rooftop temperature is 33.5 which is 14.5 below the rooftop temperature without roof pond at peak time $2 \mathrm{pm}$ to $3 \mathrm{pm}$. This finding is most promising. The pumping can be automated as a further study using solenoid switches and microcontrollers.

\section{Conclusion}

Housing and workplace comfort study observed that on an average of 60 to $70 \%$ of medium income group to the high-income group used RCC roofs. Hence during peak summer $50 \%$ of productive time is facing unhealthy and discomfort situation and leads to low productivity. Room temperature achieved is near to limits of thermal comfort stated by ASHRAE. However, the research proposed consideration this as the null hypothesis to throw light towards a water medium cooling system. The seminal effort is proposed for water medium cooling system. Further research is needed to investigate the evaporation losses of water, to accomplish improved effectiveness. Additionally, the association among water temperatures and specific climatic parameters can be also examined to suggest a mathematical model assessing the cooling efficiency of the system for particular climatic situations. The heat capacity of water reduces the variation of the inside air temperature agreeing to the observations made in this study. 


\section{References}

1. Bencheikh, Hamida\&Bouchair, Ammar. (2008). Experimental Studies of a Passive Cooling Roof in Hot Arid Areas. The Open Fuels \& Energy Science Journal. 1. 1-6. 10.2174/1876973X00801010001.

2. Givoni B. Indoor temperature reduction by passive cooling systems, Solar Energy 85 (2011) 1692-1726.

3. Kruger et al. (2016) E. Krüger, L. Fernandes, S. Lange, Thermal performance of different configurations of a roof pond-based system for subtropical conditions, Building and Environment 107 (2016) 90-98.

4. A. Sharifi, Y. Yamagata, Roof ponds as passive heating and cooling systems: a systematic review, Appl. Energy 160 (2015) 336-357.

5. Carlos J. Esparza L., Carlos Escobar del Pozo, Adolfo Gómez A, Gabriel Gómez A., Eduardo Gonzalez C, Potential of a wet fabric device as a roof evaporative cooling solution: Mathematical and experimental analysis, Journal of Building Engineering 19 (2018) 366375.

6. QairunizaRoslan, SitiHalipah Ibrahim, RohaidaAffandi, MohdNasrunMohdNawi, AzhailiBaharun, A literature review on the improvement strategies of passive design for the roofing system of the modern house in a hot and humid climate region, Frontiers of Architectural Research, 2016;5:126-133

7. K. D. Singh and S. T. Ahmed, "Systematic Linear Word String Recognition and Evaluation Technique," 2020 International Conference on Communication and Signal Processing (ICCSP), Chennai, India, 2020, pp. 0545-0548, doi: 10.1109/ICCSP48568.2020.9182044

8. S. T. Ahmed, H. K. Priyanka, S. Attar and A. Patted, "Cataract density ratio analysis under color image processing approach," 2017 International Conference on Intelligent Computing and Control Systems (ICICCS), Madurai, 2017, pp. 178-180, doi: 10.1109/ICCONS.2017.8250705.

9. S. T. Ahmed and K. K. Patil, "An investigative study on motifs extracted features on real time big-data signals," 2016 International Conference on Emerging Technological Trends (ICETT), Kollam, 2016, pp. 1-4, doi: 10.1109/ICETT.2016.7873721. 